\title{
Babies removed from their parents at birth: 160 statutory care actions
}

\author{
ANTHONY C FAIRBURN, ALAN W TREDINNICK
}

\section{Summary and conclusions}

A total of 160 babies taken statutorily into care at or soon after birth in Britain have so far been traced, mostly since 1973. Both this and the figure of 47 such actions between April 1978 and March 1979 are almost certainly underestimates. In 144 instances child abuse or neglect or both had occurred in most $(\mathbf{7 6} \%)$, but statutory action was also reported in 16 first-born babies. Schizophrenia and severe mental handicap in the parents accounted for $13 \%$, major psychiatric factors being reported in half the cases.

The practice is more widespread than was generally imagined, with doctors and nurses always concerned. More detailed surveillance of statutory care actions at birth and in the first three months of life is recommended.

\section{Introduction}

Any child for its own protection may be taken away from its parents for a short time by the police or after urgent application to a magistrate by a social services department but without the parents' right to representation. ${ }^{1}$

Since the publicity about certain inquiries into children's deaths from abuse or neglect ${ }^{2-4}$ the need of very young children for protection has come to the forefront. Correspondingly, when a child's physical and mental development is at risk, there has been greater willingness to use the existing powers for earlier

Avon and Wiltshire Area Health Authorities, Bath

ANTHONY C FAIRBURN, MRCPSYCH, FRCP, consultant child psychiatrist

Department of Social Services, Bath

A W TREDINNICK, BA, PSW, area social services officer, Bath (present appointment: assistant director of social services, Cornwall County Council) and more radical action. We became interested in how such powers are used to take a new-born baby away from its parentsthat is, before "bonding" and attachment can take place-when we were concerned in statutory removals of five new-born babies in Avon and Wiltshire, but we found only scanty experience of such procedures and few published reports.

Three earlier papers by $\mathrm{ACF}^{5}$ ( (and a paper on removal of the newborn on to care at birth presented at the 2 nd International Congress on Child Abuse and Neglect, 1978) invited views on what were acceptable criteria and justification for such a procedure, emphasising the need for honesty if the reason was simply a shortage of resources and offering ideas on the most humane and constructive way to carry out such a decision.

Although inquiries disclosed that professional opinion has moved towards accepting this as an occasional measure both in Britain and other western countries, there were no organised data. Hence we undertook a national survey, and we describe our preliminary results.

\section{Method}

A questionnaire was sent to the directors of all 132 social services in England, Wales, Scotland, and Northern Ireland requesting them to check records of place of safety orders for 1978-9 and of any held for previous years, as well as personal recollections of cases. We asked for a summary of the statutory legal instruments employed, details of appeals or revocation applications by parents, and answers to the following specific questions: what was the reason for the removal; when was the parent advised of the intention to apply for removal; what was the long-term placement plan; what arrangements for parental access were made; and what was the final outcome?

A further section asking, "What lessons were learnt ?" was attached, with a blank sheet, for suggested thoughts about moral or ethical aspects of the statutory action or of difficulties experienced with medical, nursing, or social work colleagues. Anonymity and total discretion were promised. Each baby taken into care was identified to us by an index number allocated by the staff members of each department who co-ordinated the returns. 


\section{Results and comment}

\section{INCIDENCE}

Of the 132 social services departments in Britain, $80(61 \%)$ replied: 54 returned details of cases, 22 said that they had no experience, and four refused information. Many referred to lack of statistical staff time; one department was prepared to search, but we could not find the $£ 25$ search fee requested. Some 155 incidents of babies taken into care at birth were returned by the 54 departments and by four paediatric departments which had heard of the survey. Five sets of twins gave a total of 160 babies. The twinning incidence was high$4 \cdot 1 \%$. Data were inadequate in 11 cases and limited the analysis to 144 incidents. Several cases in which the statutory order was delayed until the tenth day of the puerperium were included when there was clear evidence of preparations before birth to remove into care. Most such incidents had occurred within 24 hours of birth.

The highest number from a single social service area was eight. Most departments (28) reported one case, but 25 reported 2-5 cases and five $6-8$. Two of the last were rural, two semi-urban, and only one a large conurbation.

\section{ANNUAL INCIDENCE}

From April 1978 to March 197936 (27\%) departments reported 47 cases-the nearest to a recent annual rate that could be calculated. The annual incidence since 1967 (table I) is probably an underestimate, and we have also learnt from paediatricians, from two out of four national newspaper reports, ${ }^{7-10}$ and from two journals ${ }^{11} 12$ of other instances in both the responding and the non-responding departments' areas.

TABLE I-Number of newborn "removal" incidents reported a year (141 dated actions, twins counted as one) (data on 121 cases)

\begin{tabular}{lcccccccccc}
\hline & 1967 & 68 & 70 & 73 & 74 & 75 & 76 & 77 & 78 & $79(\mathrm{mid})$ \\
\hline No of incidents & 1 & 1 & 1 & 5 & 10 & 16 & 24 & 20 & 42 & 21
\end{tabular}

\section{BIRTH ORDER}

At least 16 were first born, a surprising finding; second and third children were most common (table II). With few exceptions, existing live children were already in care or with the extended family. Three families had had their last two children taken into care successively at birth.

TABLE II-Birth order of "removed" child (data on 121 cases)

\begin{tabular}{lcccccccc}
\hline Birth order & 1st & 2nd & 3rd & 4th & 5 th & 6 th & 7 th & 8th \\
\hline No of children & 16 & 40 & 41 & 14 & 7 & 1 & 1 & 1 \\
\hline
\end{tabular}

\section{REASONS FOR REMOVAL}

\section{Mental illness}

Seven mothers and two fathers individually suffered from schizophrenia and in three other couples this affected both parents; in each case mental disorder was given as the prime reason. Twenty other reports referred to the mother's mental illness, psychopathy, or severe personality disorder, nearly always combined with seriously defective child care or with details of the inadequate life led by the parents. Similarly, four reports mentioned "mental illness" in the fathers, and in two, such illness in both parents (one couple had met in a mental hospital). Total $38(26 \%)$.

\section{Mental handicap}

Severe mental handicap was given as the prime reason in seven mothers (one living with her own mentally handicapped mother). Twenty-two mothers, two fathers, and two couples suffered from a combination of dullness, educational subnormality, or borderline mental handicap with personality disorder, and other multiple social or defective parenting factors. One new cohabitee in a multiple-child family had been seriously damaged in a motorbike accident. Total $31(22 \%)$.

In these parents with dullness and combined factors most had abused or severely neglected earlier children. We discuss below the problem that such intellectually dull people might have in putting up a defence against statutory intervention.

\section{Child abuse, violence, and neglect}

Child abuse had previously occurred in 80 cases, just under half combined with child neglect. Eighteen previous children were dead, 12 of them killed by their parents (fathers six, mothers five, both parents one): six had died "in suspicious circumstances" with child abuse suspected in three, while three cot deaths were also recorded. Subsequent to one such unexplained death, exhumation by the police had disclosed multiple fractures in the dead baby which lead to the decision during the next pregnancy to take statutory action at birth.

A few of the living children in these families were blind, unable to speak, paralysed or mentally handicapped or both as a result of earlier parental violence.

In 11 cases the parents (four mothers and seven fathers) had been convicted of killing an earlier or other child; 22 (10 fathers, eight mothers, four both) had been convicted for injuring earlier children with the usual mixed pattern of limb and skull fractures, severe bruising, cigarette burns, a salicylate overdose, and coma from a huge overdose of salt. In four other cases charges of killing had been prepared but had not been successful.

Thus in one-quarter of the cases there had been parental charges or convictions for earlier child abuse (19 fathers, 14 mothers, five both).

\section{General violence, criminality, sexual abuse}

General violence was recorded in five cases other than the above, such as (mother) "stabbed cohabitee," "previous offence against niece"/". . . against relative's child"; "threatened to knife the other babies in the nursery"; or (father) "violence in the hospital"; two (in cases of neglect only) described as "homicidal"/"violent psychopath"; and a "very violent" step-father who had threatened the children with a syringe. One cohabitee had arranged a booby trap explosive device for visiting professionals. Two mothers were serving prison sentences for unstated reasons at the time of pregnancy, another was on probation, and one went to prison later on a shoplifting charge-when the supervision order was converted to a care order.

Sexual abuse was mentioned in only one case.

\section{NEGLECT}

Neglect of earlier children had occurred in 61 cases (neglect alone 27 , combined with child abuse 34). Many reports referred also to hypothermia, malnutrition, failure to seek medical help in illness, and gross emotional deprivation factors. One previous child of a schizophrenic mother had died of neglect.

In eight cases of neglect without evidence of previous child abuse there were descriptions of parental aggressiveness, dangerousness, or marital or neighbourhood violence (four mothers, three fathers).

\section{Other miscellaneous factors}

In 13 cases ( $9 \%$ ) parental mental illness and severe mental handicap, parental dullness combined with personality disorder and other social factors, child abuse, and serious child neglect were not given as the prime reason.

Two couples had moved shortly before the birth with a history of existing children taken into care in other counties but without adequate information. Both were Chinese and were felt to have moved through loss of face to have the next baby elsewhere. The place of safety order taken on the new-born baby had then allowed time for inquiries, and each baby was rehabilitated quickly back with its parents.

Two couples were Jehovah's Witnesses, one very young, were able to stay with their babies and co-operate throughout the brief statutory actions for transfusion treatment. In nine other cases the mother's "way of life" was cited. All were single, unstable, and, in three cases, homeless or nomadic. Two were described as prostitutes; three were alcohol dependent (1) or heroin addicts (2), one injecting into the breast from which the baby was feeding (two babies in the survey experienced heroin withdrawal symptoms at birth, one developing convulsions). Those mothers who had homes had showed extreme emotional instability or behaviour disturbance.

Eight of the 13 babies in this miscellaneous category were rehabilitated, though in three instances this was by default of the care order going through and, in another five the departments clearly remained uneasy about the outcome. Three were subsequently taken 
back into care, one adopted after an abandonment, one adopted by consent after constructive attempts at access, and one adopted as a result of radical action taken a year later (in a heroin addict).

Hence in most of this group the "sociological" criteria determined at birth were valid and were not used vaguely to control the whereabouts of mother and child during a perinatal assessment.

\section{Marital factors}

At least 48 mothers were single (12 educationally subnormal) and in all but one case-in which the putative father had been convicted of manslaughter-there were strong factors operating of immaturity, instability, psychiatric disturbance, or a nomadic way of life (table III).

Marital data were not requested in this survey so the seven marriages breaking up at the time, the 11 cohabitations, and three step-parents mentioned are probably underestimates, in each instance described with major personality or behavioural disturbance. Some returns for earlier years indicate that several of the couples separated during the follow-up period.

\section{TABLE III-Details of 48 single mothers}

\begin{tabular}{|c|c|c|c|c|c|c|c|c|}
\hline \multicolumn{9}{|c|}{ Predominantly psychiatric factors (some with child abus } \\
\hline \multicolumn{9}{|c|}{ Severe mental handicap $\quad \ldots \quad \ldots \quad \ldots$} \\
\hline ESN with multiple social fa & tors & .. & .. & .. & .. & .. & . & 14 \\
\hline Schizophrenia. & & . & . & $\cdots$ & . & . & & 2 \\
\hline \multicolumn{9}{|c|}{$\begin{array}{l}\text { Mental ill-health with social factors } \\
\text { Defective parenting mainly }\end{array}$} \\
\hline Child abuse (2) with neglect & & . & $\ldots$ & $\ldots$ & . & .. & . . & 8 \\
\hline Neglect (3), general inadequ & cy (2) & . & . & .. & . & . & . & 5 \\
\hline \multicolumn{9}{|l|}{ Other } \\
\hline $\begin{array}{l}\text { Itinerant, nomadic } \\
\text { Drugs/alcohol dependency }\end{array}$ & . & $\because$ & $\because$ & $\because$ & $\because$ & $\because$ & $\cdot$ & $\begin{array}{l}5 \\
3\end{array}$ \\
\hline Prostitute & . & . & . & . & . & . & . & 2 \\
\hline
\end{tabular}

$\mathrm{ESN}=$ Educationally subnormal

\section{LEGAL INSTRUMENTS*}

A place of safety order was usually the first instrument, but 78 cases went straight on to full care orders, 13 to section 2 resolutions (Children's and Young Persons Act 1948), and 8 to wardship-a total of 99 . Six care actions failed but reapplication was successful in three; another was pending.

Ten parents had applied for revocation of care orders, but only one had succeeded. Another application was pending four and a half years after removal at birth after a disastrous late breakdown of fostering.

Six late care orders had come after a trial of allowing the baby home with its mother (one after eight months' attempts to achieve "bonding" in a nursery), two after magistrates had initially granted a supervision order only, and one after abandonment.

Some 15 cases had gone on to supervision orders, but five of these had ultimately become full care orders; in other words 10 babies had remained under supervision as a result of courts acting contrary to the advice of professional departments.

Section 1 (Children's and Young Persons Act 1948) was the only measure in eight, mostly cases for perinatal assessment. Fourteen had gone on to section 2 or full care orders. Five parents appealed against section 2 resolutions, one successfully but the child was in care again.

Guardianship was invoked in one baby who stayed with its parents.

Wardship-Four authorities were responsible for 11 successful applications for wardship, two showing an obvious special interest in the measure. Its outcome was sometimes delayed to as late as the sixth or ninth month, but we have been advised by $\mathrm{Mr}$ Richard White ${ }^{13}$ that interim wardships may be granted on the day of birth-preferably after careful legal consultation-and that subsequent procedures can be speeded up if an energetic case is made.

\section{Delays}

In six cases a baby's status was unresolved because the local hearing might have prejudiced or have been prejudiced by pending criminal prosecutions of parents, including two charges of murder. Such current prosecutions, as well as strike action, accounted for most delays. Technicalities varied from the early High Court blocking action brought by one obviously well-advised couple to a few late actions, sometimes by understandably bitter parents or when a psychiatric condition relapsed. Nothing quite like the action for "false imprisonment" was met, reported (in a case not in our series) by one national newspaper. ${ }^{9}$ Table IV shows the final legal status of the babies.

*Nearest English equivalent given in Northern Irish and Scottish cases.
TABLE IV-Final legal status of 144 babies

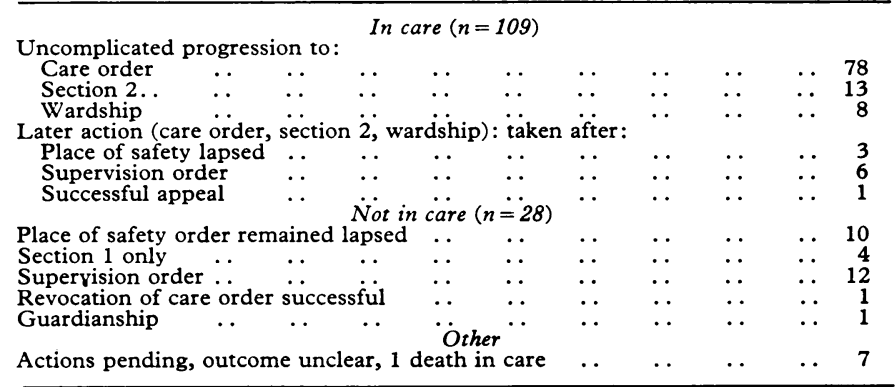

\section{Legal difficulties}

There were few cases in which legal difficulties were described or seemed to have resulted from a lack of parents' legal representation. There were, however, several instances of mothers failing to attend for court hearings, or of professional colleagues who withheld co-operation. These included other social workers-for example, probation officers-and some doctors and nurses who did not support agreed courses of action or who were considered to have over-identified with parents, at the expense of the needs of the child.

\section{Parents who fought}

Examples of the parents who fought to retain their children are:

(1) A mother on probation whose first child had been adopted after a sequence of nine fractures, dislocated elbow, and cigarette burns achieved revocation of care order when her second baby had spent six months in a children's home. In this case the social worker commented that the availability of a mother-and-baby home (to keep them both together) would have been an acceptable alternative to statutory action at birth.

(2) Another mother who had committed manslaughter at the age of 14 and who had been charged for the second of two cot deaths and found not guilty, was living with her second husband. The department's plan to foster and adopt the third child was unsuccessful when these well-represented parents, in a wardship action in which care was given to the local authority, managed to get included a rider that the child should remain with the parents. They had previously refused to release the baby at birth before seeing the documents.

(3) In a case in which two previous children had both had severe non-accidental injuries obviously well-advised parents took the case immediately to the High Court in a wardship application, which would have had the effect of blocking local magistrates' court proceedings. Eventually a wardship with care and control to the local authority was achieved. The birth of a fourth child was subsequently disguised from the department. The social worker commented, "a new and not-to-be-repeated experience."

\section{Fehovah's Witnesses}

In both cases where Jehovah's Witnesses were concerned the statutory action (taken in 1973 and 1976 on medical insistence) was judged in retrospect to be theoretically unnecessary. The Department of Health and Social Security circular F/P9/IB of 1967 and that of the Scottish Home and Health Department HOS/2/298 of 1975 assured hospital authorities of support when life-saving procedures are carried out on children whose parents refuse permission-with recording safeguards. In one case two bedside hearings and one in chambers might have been avoided. In the other, the parents, aware of the possibility of death and having made their point, were totally co-operative.

\section{ASPECTS OF MANAGEMENT}

\section{Telling the parents}

A total of 54 parents were known to have been told of the social services department's decision before the baby was born. Nineteen mothers were in their first trimester, eight between the fourth and eighth month, and seven in the month before birth, though difficulties arose when the estimated dates of delivery were not accurate and the baby was born prematurely. In 20 the point of telling was not known.

In 68 instances the parents were definitely not told of the decision until after the birth, generally when the order was served. This time was mostly up to the third or fourth day-in a few cases around the 
tenth day and in a couple at the fifth week. In cases with considerable delay a firm intention and planning for statutory action were reasonably clear. There were some indications for delay in telling, such as "... when the mother was rational," ". . . the mother in custody awaiting trial," or ". . . unable to understand the proceedings"; but there were also two mothers "expecting such action and in suspense" who had not been told before the birth. Two couples were told of the intention before the birth of the child and were advised at the same time not to have further children.

\section{"Short-episode" cases}

In 27 instances-that is, just under one in six of all babies in the survey-the statutory intervention had been short lived. These 27 short-term cases fell into four rough categories.

Firstly, briefly to control the mother and child (16): while another authority was urgently contacted (two); while solving a homelessness crisis (with other factors) in late pregnancy (three); to allow assessment of bonding and attachment-mentioned specifically (three); for assessment of the total situation (four, one in psychiatric day care); while two babies who were Jehovah's Witnesses were treated; and to allow fostering arrangements with grandparents (two). The second category is where there were deep professional misgivings, or a department was clearly leaning over backwards to give parents a chance (four cases). Thirdly, the care order was lost, so that the baby went home unplanned (four), including one successful parental legal battle. Finally, there was no apparent clear plan from the record we received in three.

\section{First-born babies}

Of the 16 first-born babies, three had schizophrenic or "psychotic" mothers: one both parents; one of these also had a schizophrenic maternal grandmother and one a father aged 81 . Six had mothers with "mental illness": one both parents, five mothers being single, and of these another had a schizophrenic maternal grandmother. Four mothers had personality disorders (two both parents), including one heroin addict. Three mothers were educationally subnormal or "low educationally subnormal," two of them being single.

Four first-born babies (all with single mothers) were successfully rehabilitated home. In three others this was tried (one after an unsuccessful care application), but eventually the children went to foster parents.

\section{Abandonment}

Abandonment was a factor in ten, cases. Five mothers had abandoned previous children. In the survey six had abandoned a baby, and this included one of the former. All abandonments occurred early, and most cases had been expected. In one, a prostitute with tuberculosis, the place of safety order had just lapsed as it had been thought that there were "no grounds for a care order"; the social worker commented, "It would have been better in this case to have taken the initiative. ..."

\section{Outcome for the baby}

Of 28 babies who still remain with their parents, this had been planned in 15 cases, in four there being mention of assessment. Two babies had returned home on supervision orders. In the other 13 cases the outcome was unplanned, in one case there being evidence of assessment, while another was on a supervision order. One baby returned home unplanned when the natural father was jailed and mother remarried, and another when wardship was granted but with the rider to return to the parents' home. Three of the unplanned returns sound extremely hazardous given the details of severe damage to earlier children of the family.

Of the remaining 83 known to have been placed into care, 38 were still with long-term foster parents, 34 had proceeded to adoption by the foster parents, and 11 others had been adopted. Five had been placed within the extended family (if one mother's foster home is counted as such), another with the mother in the maternal grandparental home, two others to maternal grandparents (one with a sibling), and one to paternal grandparents. Two babies had finished up in a residential nursery, in one case after the parents had turned out to be too hostile to accept supervision and in the other after a trial with mother in the homeless families unit. In three cases local authorities took further action after the children had returned homeone being taken into care after desertion, and two had care actions pending.

Of the parents who acted after long-term placement, one couple was seeking revocation of a care order four and a half years after placement with foster parents that had broken down. Two had unsuccessfully opposed foster placements, one disappearing shortly after starting the action. One child was with foster parents who wished to adopt, but the father (the mother being schizophrenic) was withholding consent. In only one case had adoption consent been dispensed with.

Those whose futures were unresolved included mothers appealing against sentence or awaiting trial, a wardship under way, and a late application for a care order after a department had made extreme efforts to keep the parents and child together.

Four infants died-the twin (not counted in the survey) of a $1361 \mathrm{~g}$ premature baby with respiratory distress and meningitis; one of bronchiolitis on day 22; one at 9 months in a residential nursery; and one of congenital heart disease at 3 years, in fostering.

\section{Discussion}

Our national survey into how far professional people are prepared to start radical care actions for new-born babies suffers from two limitations: its incompleteness and its reliance on the collective memories of departments that had been twice reorganised. The psychiatric data in particular will need elucidation. Nevertheless, there were indications that the practice has become more acceptable, for at least $44 \%$ of social services departments have now had this experience and many respondents were categorical about the rightness of their action at an especially difficult time. Others are still uneasy about the statutory intervention by a department at childbirth when massive help might have been given to single mothers and deprived, disturbed couples to care for their young child on their own. Given the special nature of such an intervention so close to childbirth, in parents with no chance to prove themselves with the baby in question, the technical arguments for or against removal are those cited in all child care proceedings, using the criteria of the 1969 Children's Act. These are a history of injury or grave emotional or other deprivation to earlier children, or the presence of an adult in the household who has injured or neglected a previous child. Nevertheless, the statute does not cover the reasoning over first-born children. Here may be a place for wardship, with its inherent flexibility.

Certain points arise from our study which illustrate the complexities of the questions.

(1) How may the ability of the parents be assessed in young and inexperienced people with no child to handle?

(2) With what accuracy can one extrapolate disturbed and damaging behaviour towards an earlier child to that with subsequent babies?

(3) What consideration should be given to the older children of the family to be with their parents, with whom they have formed attachments, by contrast to parental desire to start on a clean slate with a new baby? Should the statutory agencies resolve this balance of their children's rights?

(4) What predictions are to be made with a change of spouse or cohabitee?

(5) How should one manage the consultation for parents faced with mutually exclusive choices in a pregnancy-for example, the mother who has to decide between relinquishing the spouse or the baby?

Another problem occurs when doctors (paediatrician, obstetrician, psychiatrist, or family doctor) and obstetric nurses very occasionally withhold crucial collaboration-for instance, a medical refusal to confirm the new pregnancy on its way, or, because of confusion, nurses who encourage "bonding" in a mother who is shortly to have her baby taken away for ever. Nevertheless, at the other extreme, many authorities do have adequately prepared social, legal, medical, and nursing organisations which can make clear, definite policies that, while less destructive of both parents and professionals, ensure the babies' long-term futures.

Some might see such a well-prepared team as a danger. Some may question the inevitable absence of legal representation and 
of overt safeguards (in England) for the parents at the crux of the action, especially the dull and mentally handicapped. We believe that arrangements for reporting care actions in under-5s should be changed, separating out all instances of statutory removal of the newborn and children in their first three months of life. This would allow more detailed scrutiny of very early care actions and maternal abandonment for research and would enable better evaluation of a practice that has emerged tentatively over the past ten years. It would also provide more answers to questions about the drastic use of statutory powers and would, we believe, place the procedure in the context of all child care. proceedings. We believe that removal at birth is occasionally necessary and appropriate, but that more information is needed before proper criteria can be recognised and agreed. We had, for instance, wrongly assumed that psychotic illness or severe mental handicap only would justify removal of first-born children.

Care will be needed in avoiding some extremes of intervention in the perinatal period, when all that may be required is to hold the mother and baby together while further inquiries and assessment are set in motion, as advocated recently by $\mathrm{Dr}$ Christina Cooper. ${ }^{14}$ Donald Bross, in a paper presented at the 2nd International Congress on Child Abuse and Neglect in 1978 , suggested ways in which various US State laws might be used to bring about some control over a woman in late pregnancy and at childbirth. In Britain wardship might be tried ${ }^{13}$ to treat mother and baby as one entity, a particularly relevant possibility as more mother-and-child residential assessment units are developed.

We thank Miss P Thayer and Mr G C Lupton of the DHSS and Mr $\mathrm{H} \mathrm{N}$ Grindrod and Miss $P$ M Farrell of the Association of
Directors of Social Services and its Research Subcommittee for encouragement and help in making the survey; Mr Andrew Edgington of Avon Social Services' research department for help in designing the questionnaire; and the hard-pressed field-work professionals who trusted us with sensitive data as well as their personal opinions.

Reprints may be obtained from Dr A C Fairburn, Department of Child Psychiatry, Royal United Hospital, Bath BA1 3NG.

\section{References}

${ }^{1}$ Black JA, Hughes F. Legal aspects of child injury or neglect. $\mathrm{Br} \mathrm{Med} \mathfrak{F}$ 1979;ii:910-2.

2 Committee of Inquiry into the care and supervision provided in relation to Maria Colwell. Report. London: HMSO, 1974.

${ }^{3}$ Committee of Inquiry into the provision and coordination of services to the family of John George Auckland. Report. London: HMSO, 1975.

4 Committee of Inquiry concerning Simon Peacock. Report. Cambridgeshire and Suffolk County Councils and Area Health Authorities, 1978.

${ }^{5}$ Fairburn AC. Statutory removal of a newborn baby. Study group of prediction and prevention of child abuse. In: White Franklin A ed. Child Abuse. London: Churchill Livingstone, 1977:175-80.

- Fairburn AC. Child Abuse and Neglect (in press).

${ }^{7}$ From birth into care. Guardian 1978 Mar 7:3 (col 6).

${ }^{8}$ Parental appeal over baby taken into care. The Times 1978 Sept 15:3 (col 5, 6).

${ }^{9}$ Council sued for baby's "imprisonment" in care. Daily Telegraph 1979 Jan 20:13 (col 4,5).

${ }^{10}$ Father who killed child loses his baby. Daily Mail 1979 Aug 24:11 (col 6).

${ }^{11}$ Melotte C. Why children are taken into care. New Society 1979 Jan 11 :75-7.

${ }^{12}$ Marcovitch H. One nation. World Medicine 1979;24:26-7.

${ }^{13}$ Lowe NV, White RAH. Wards of court. London: Butterworths, 1979.

${ }^{14}$ Cooper CE. Babies at risk. $\mathrm{Br}$ Med $\mathcal{F} 1979$;ii :792.

(Accepted 12 February 1980)

\title{
Outside Europe
}

\section{Smoking and Africa: the coming epidemic}

\author{
AHMED TAHA, KEITH BALL
}

Over the past 30 years cigarette smoking has become the main environmental cause of disease and death in many developed countries. This contrasts with the state of affairs in developing countries, where diseases of infection and malnutrition are the main source of reduced life expectation. A recent World Health Organisation report $\mathrm{t}^{1}$ directed attention to the immediate and serious threat of smoking diseases in the developing world. It considered that without strong and resolute action "smoking diseases will appear in developing countries before communicable diseases and malnutrition have been controlled." WHO's Director General recently named smoking as "Probably the largest single preventable cause of ill-health in the world."

This paper describes the development of tobacco smoking in Africa, suggests that smoking-related diseases similar to those seen in Western countries may be beginning to emerge there as well, and illustrates how consumption is rising and how this is being promoted.

Department of Community Medicine, Middlesex Hospital Medical School, Central Middlesex Hospital, London NW10 7NS

AHMED TAHA, MB, MRCP, research assistant

KEITH BALL, MD, FRCP, senior lecturer in preventive medicine

\section{The smoking habit}

Tobacco was introduced into Africa in the fourteenth century, when the Turks brought it to Egypt. ${ }^{2}$ About the year 1560 Portuguese and Spaniards brought tobacco to east Africa, and from there its cultivation spread to central, west, and south Africa. ${ }^{3}$ An English sea captain, Crowley, was the first to report tobacco smoking in Africa in the year $1607 .{ }^{4}$ Calling at Sierra Leone on his way to the East Indies, he saw "Tobacco growing in small patches and natives smoking it." The smoking habits of Africans are governed by local custom and economic status. Cigarette smoking is replacing the traditional pipe or hookah, which is still used, especially in rural areas. The prevalence of smoking is higher in urban than in rural areas, where only men used to smoke, but the proportion of women who smoke is now rising, as in Egypt. ${ }^{2}$ In Lagos $42 \%$ of men and $2.4 \%$ of women smoke cigarettes. ${ }^{5}$ In Senegal $80 \%$ of urban men but only $15 \%$ of rural men smoke cigarettes. ${ }^{6}$ In the towns smokers start younger and smoke more; $62 \%$ of black workers in a Johannesburg factory smoked cigarettes.

Smoking is increasing among African children and adolescents. Forty per cent of boys and $8.4 \%$ of girls from a Nigerian secondary school smoked. ${ }^{8}$ In Uganda $33.4 \%$ of male and $7 \%$ of female students were found to smoke and $85 \%$ of them had already started smoking before entering university. ${ }^{9}$ A South African study of 1505 children at 12 high schools showed that $16 \%$ were regular smokers. ${ }^{10}$ 